\title{
IDENTIFICAÇÃO DE ÁREAS VERDES URBANAS A PARTIR DE IMAGENS DE SATÉLITE WORLDVIEW-II: O CASO DAS PRAÇAS NA CIDADE DE MONTES CLAROS - MG IDENTIFICATION OF URBAN GREEN AREAS FROM SATELLITE IMAGES WORLDVIEW-II: THE CASE OF SQUARES IN THE CITY OF MONTES CLAROS - MG
}

\author{
Carlos Alexandre de Bortolo', Herick Lyncon Antunes Rodrigues', Mariley Gonçalves Borges \\ ${ }^{1}$ Universidade Estadual de Montes Claros, (UNIMONTES), Montes Claros, MG,Brasil
}

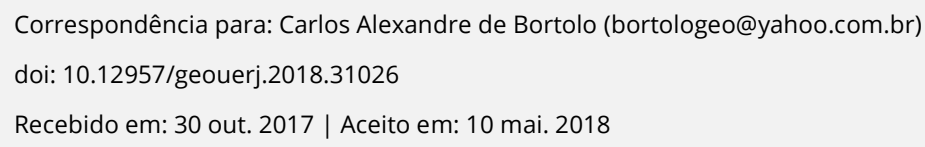

\section{RESUMO}

A existência de áreas verdes dentro da área urbana influencia diretamente na melhoria das condições ambientais e sociais. Partindo desse pressuposto, as discussões aqui expostas visam classificar as praças como áreas verdes ou espaços públicos, baseados em suas funções apresentadas, tais como, função ecológica, estética, lazer e área permeável de 70\%. Assim sendo, tendo como foco principal a cidade de Montes Claros, o presente trabalho busca aplicar os conceitos, métodos e técnicas que auxiliem na identificação, classificação, quantificação e mapeamento das praças da cidade, definindo as mesmas como área verde ou espaço livre. A metodologia utilizada na delimitação e classificação das praças baseou-se na revisão da literatura e na utilização de imagens de satélite com alta resolução espacial, assim também como trabalhos de campo. Constatou-se que as praças consideradas como áreas verdes estão dispostas de forma heterogênea na cidade, ocupando desde loteamentos com condições mais precárias até locais mais dinâmicos e estruturados, observando que ainda existem alguns locais que não dispõem dessas áreas. Conclui-se que, a cidade de Montes Claros possui cerca de noventa e seis praças, destas, oitenta e uma foram classificadas como espaços livres devido apresentarem parte ou nenhuma das funções para ser designada como área verde e dezesseis foram consideradas como áreas verdes por apresentarem todas as funções.

Palavras-chave: Imagens de Satélite; Praças; Áreas verdes; Espaços livres.

\section{ABSTRACT}

The existence of green areas within the urban area directly influences the improvement of environmental and social conditions. Based on this assumption, the discussions here aim to classify squares as green areas or public spaces, based on their presented functions, such as ecological function, esthetics, leisure and permeable area of $70 \%$. Thus, with the main focus of the city of Montes Claros, the present work seeks to apply the concepts, methods and techniques that assist in the identification, classification, quantification and mapping of the city squares, defining them as green area or free space. The methodology used in the delimitation and classification of the squares was based on the literature review and the use of satellite images with high spatial resolution, as well as in the field work. It was observed that the squares considered as green areas are arranged in a heterogeneous way in the city, occupying from subdivisions with more precarious conditions to more dynamic and structured places, noting that there are still some places that do not have these areas. It is concluded that the city of Montes Claros has about ninety-six squares, of these, eighty-one were classified as free spaces because they have part or none of the functions to be designated as green area and sixteen were considered as green areas because they presented all functions.

Keywords: Satellite Images; Squares; Green areas; Free spaces.

\section{INTRODUÇÃO}


O crescimento das cidades através do parcelamento do solo vem ocasionando transformações paisagísticas, prejudicando e comprometendo a qualidade ambiental urbana. Conforme Buccheri e Nucci (2006) através do crescimento das cidades ocorrerão à diminuição na quantidade e qualidade das áreas verdes.

Compreende-se que fatores relacionados à qualidade do ambiente como a vegetação beneficiam a população urbana de forma positiva contribuindo no seu bem-estar. Lima e Amorim (2006) salientam que dentro das cidades os problemas pertinentes ao meio ambiente tem se destacado com mais frequência, assim a necessidade de uma reforma no planejamento, através da criação de políticas que tornem a ocupação do solo no perímetro urbano menos impactantes ao meio ambiente.

A maior dificuldade enfrentada no planejamento urbano ou pelos pesquisadores da área é como definir o verde urbano. Lima et al. (1994) destacam que os diferentes tipos de conceitos utilizados para a definição de terminologias como: área de lazer, espaço livre, arborização urbana e área livre tem dificultado a aplicação do mesmo no ensino, pesquisa, planejamento ou gestão das cidades.

Conforme a Lei $n^{0} 3.720$ de maio de 2007 sobre o parcelamento do solo urbano do município de Montes Claros, a definição de áreas verdes é restrita apenas a canteiros existentes no decorrer das vias que possuem área superior a 20 metros. Entretanto, baseado nos estudos de Cavalheiro et al. (1999), esses canteiros podem ser considerados como verde de acompanhamento viário e não como áreas verdes, uma vez que não apresenta as características necessárias.

$\mathrm{Na}$ literatura, as áreas verdes são interpretadas de várias formas com definição e características bem diferenciadas. Cavalheiro et al. (1999) destacam as áreas verdes como parte integrante do grupo dos espaços livres, onde a principal característica que as diferenciam é a vegetação.

Tendo como foco principal a cidade de Montes Claros, o presente trabalho busca aplicar os conceitos, métodos e técnicas que auxiliem na identificação, classificação, quantificação e mapeamento das praças 
da cidade, definindo as mesmas como área verde ou espaço livre de acordo com as sugestões feitas por Cavalheiro et al. (1999).

O desenvolvimento desse trabalho é importante, uma vez que contribui para melhoria da qualidade ambiental urbana, beneficiando dessa maneira toda a população do local onde está inserida.

É importante destacar que embora existam parques urbanos em Montes Claros que poderiam ser enquadrados como áreas verdes, tais como o Parque Milton Prates, o Parque das Mangueiras e o Parque Sapucaia, os mesmos não foram considerados neste trabalho, uma vez que visamos empregar a metodologia trabalhada por Cavalheiro et al. (1999) à cidade de Montes Claros na classificação das praças como áreas verdes ou espaços livres.

\section{MATERIAIS E MÉTODOS}

\section{Caracterização da Área de Estudo}

O município de Montes Claros está situado no norte do estado de Minas Gerais, entre as coordenadas geográficas $16^{\circ} 40^{\prime} 30^{\prime \prime}$ e $16^{\circ} 47^{\prime} 30^{\prime}$ de latitude sul e $43^{\circ} 54^{\prime} 30^{\prime \prime}$ e $43^{\circ} 47^{\prime} 30^{\prime}$ longitude oeste (Figura 1) sendo limítrofe aos municípios de São João da Ponte, Patis, Mirabela, Coração de Jesus São João da Lagoa, Claro dos Poções, Bocaiúva, Glaucilândia, Juramento, Francisco Sá e Capitão Enéas. Com uma área de 3.568,9 km² , densidade demográfica de 101,41 hab $/ \mathrm{km}^{2}$, possuindo um PIB, no ano de 2010, de 5.335.046 mil reais e uma população de aproximadamente 361.915 habitantes. Desse total, 338.381 ocupam a sede municipal, 344.427 a área urbana do município e 17.488 residem na zona rural (IBGE, 2010). 


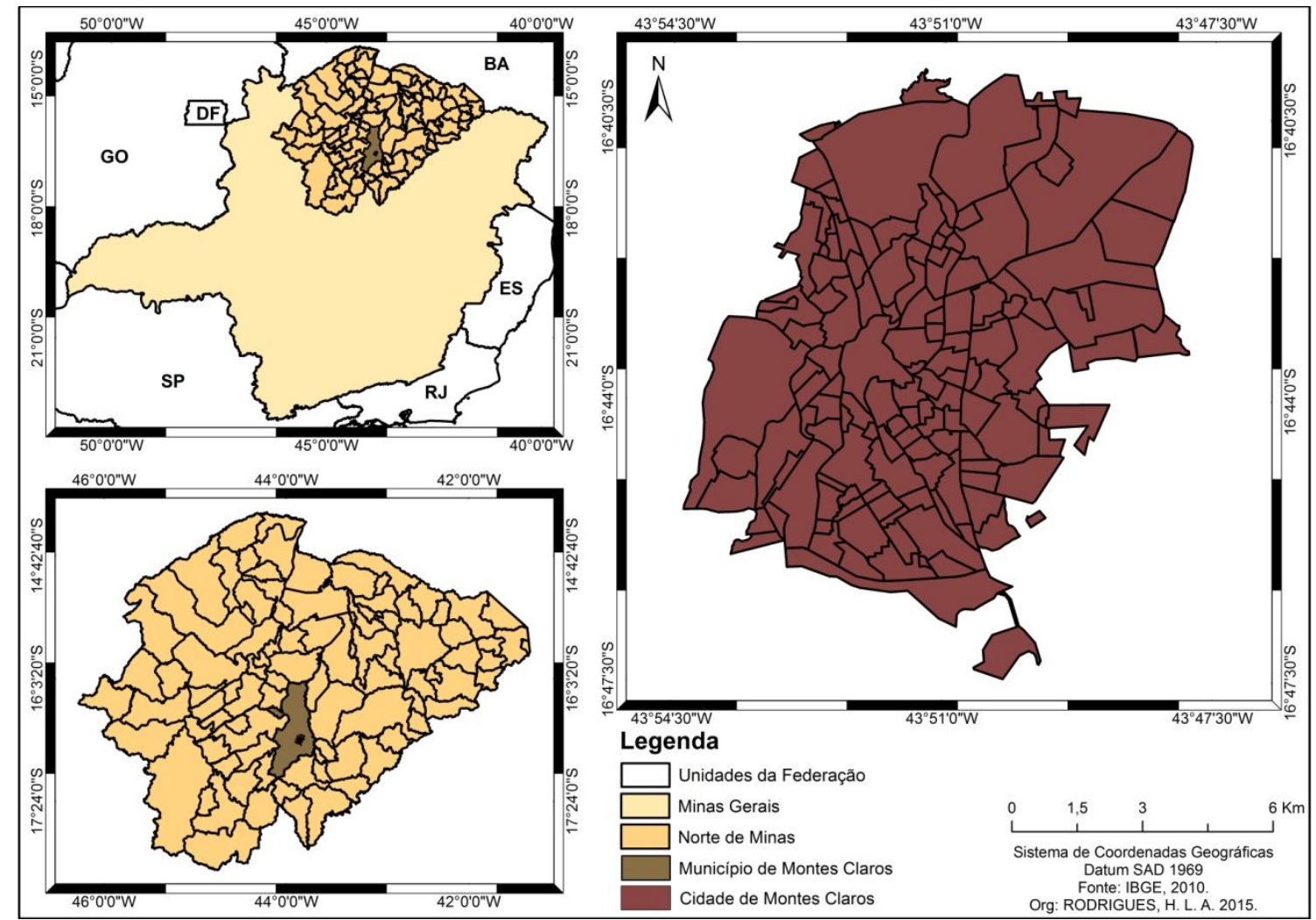

Figura 1. Localização da Cidade de Montes Claros

Fonte: IBGE,2010

Segundo a última divisão administrativa datada em 2001 o município é constituído pela sede municipal Montes Claros e pelos distritos de Aparecida do Mundo Novo, Ermidinha, Miralta, Nova Esperança, Panorâmica, Santa Rosa de Lima, São João da Vereda, São Pedro das Garças, Canto do Engenho e Vila Nova de Minas (IBGE, 2010).

\section{Procedimentos Técnicos}

Com o objetivo de analisar, mapear e classificar as praças como áreas verdes ou espaços livres na cidade de Montes Claros os procedimentos técnicos utilizados conforme a proposta do estudo dividiu-se em quatro etapas.

A primeira etapa constitui-se no levantamento e revisão bibliográfica visando à busca por uma fundamentação teórica sobre o tema tratado e sobre a área estudada, com base em artigos de periódicos, teses, dissertações, monografias, etc. 
A segunda etapa do trabalho estabeleceu-se com a coleta e construção da base de dados a partir de imagens do satélite WorldView-II cedido pelo Laboratório de Geoprocessamento da Universidade Estadual de Montes Claros (Unimontes), e a base de dados do perímetro urbano de Montes Claros em formato Shapefile disponibilizados pela Prefeitura Municipal de Montes Claros. Através desses produtos foi iniciado o processo de mapeamento e vetorização das praças. Primeiramente inseriu-se a imagem no software ArcGis 10.2 juntamente com o shapefile do perímetro urbano, criou-se um shapefile de Point e outro de Polígon para localização e delimitação da área em m2 ocupado pelas praças e com o auxílio da ferramenta Street View do Google Earth possibilitou a visualização para análise da situação das praças na cidade.

Na terceira etapa após a criação dos vetores das praças e da análise das funções feitas a partir do Street View conforme os conceitos apresentados por Cavalheiro (1999) houve a necessidade de validação desses dados em campo. Desta forma, ainda de acordo com o autor supracitado, as funções utilizadas para classificação dessas áreas foram à ecológica, que se relaciona a melhoria das condições do ar, conservação da fauna e do microclima, a estética considerando a aparência do local, o lazer que se refere a um lugar de repouso, descontração ou tranquilidade e área permeável de $70 \%$.

Finalizado os processos de construção da base de dados e validação em campo, na quarta etapa, foram gerados mapas de localização da cidade de Montes Claros e das praças e a geração de tabela com a classificação das praças de acordo com as funções apresentadas, destacando as praças que foram definidas como áreas verdes.

\section{RESULTADOS E DISCUSSÃO}

Uma das características que deveria ter bastante importância dentro das cidades, porém muitas vezes é deixada de lado dentro do seu desenvolvimento é a cobertura vegetal conforme abordado por Nucci (2001). A vegetação é importante para o ser humano dentro da cidade, pois além de ser necessária devido a sua influência na melhoria das condições ambientais e sociais, vários problemas enfrentados como a poluição do ar e dos rios poderiam ser amenizados com a preservação da vegetação. 
Desde a antiguidade, as áreas verdes tinham funções relacionadas a passeios, locais de repouso ou voltadas a atividades recreativas, más, na atualidade devido a diversos problemas como a poluição atmosférica gerado nas cidades, elas têm sido vistas também com propósito de proteção do meio ambiente dentro dos espaços urbanos. Lima e Amorim (2006) ressaltam que essas áreas são destinadas a comportar o verde urbano, podendo ser também um indicador importante para análise da qualidade ambiental urbana.

De acordo com Cavalheiro e Del Picchia (1992) a principal ideia quando discorremos sobre o termo áreas verdes menciona o quão abrangente possa ser. Bargos e Matias (2011) destacam que termos como áreas verdes, espaços livres, arborização urbana, verde urbano, dentre outros, são empregados com bastante frequência para categorizar e dar significado a expressão "vegetação urbana".

Esses termos são utilizados de forma frequente por órgãos públicos voltados para o planejamento municipal e também dentro do âmbito acadêmico gerando uma divergência com relação ao conceito das áreas verdes, dificultando o mapeamento e identificação.

O planejamento e a gestão dessas áreas são delimitados conforme os moldes do plano diretor da cidade. Londe e Mendes (2014) expõem que de forma geral, conforme os critérios que são expostos dentro do plano diretor, o termo possui uma característica bastante abrangente, referindo-se as áreas verdes como espaços onde há o predomínio de vegetação, incorporando praças, jardins, unidades de conservação, canteiros centrais de ruas e avenidas, trevos e rotatórias de vias públicas. No entanto, destaca-se que boa parte não possui cobertura vegetal e apresenta uma má qualidade de infraestrutura.

Para padronização dos conceitos, Cavalheiro et al. (1999) sugeriram alguns tópicos buscando entender primeiramente a legislação estabelecida no Brasil, onde cada município está dividido em três parcelas denominadas de zona urbana, expansão urbana e zona rural.

Conforme os autores supracitados, a zona urbana embora não possua seu perímetro declarado por determinada Lei municipal, estaria formada por três sistemas: "Sistema de espaços com construções 
(habitação, indústria, comércio, hospitais, escolas, etc.); Sistema de espaços livres de construção (praças, parques, águas superficiais, etc.) e Sistema de espaços de integração urbana (rede rodoferroviária)" (CAVALHEIRO et al., 1999, s/n).

O sistema de espaços livres de construção ou espaços livres definido pelos autores englobam locais ao ar livre voltados para diversas práticas esportivas, repouso e de forma geral recreativa, buscando métodos para entreter seus visitantes, disponibilizando também lugares para passeios e caminhadas que sejam seguros e ofereçam comodidade através de percursos prazerosos e diversificados, lembrando que, locais onde ocorre a locomoção de pessoas através de veículos motorizados não são considerados espaços livres.

Conforme Cavalheiro et al. (1999) esses espaços considerados livres podem ser classificados de três maneiras quando relacionado a restrição do seu uso, sendo tidos como públicos, potencialmente coletivos ou privados, desempenhando funções predominantes como estética, lazer, ecológicoambiental, etc.

Já as áreas verdes definidas pelo mesmo autor, são tidas como uma subcategoria dos espaços livres, onde o principal elemento é a vegetação. São apontados três objetivos primordiais que devem se estabelecer dentro dessa área, sendo o ecológico-ambiental, estético, lazer e possuindo solo permeável que preencham $70 \%$ da área total.

Áreas dentro do perímetro urbano como rotatórias, arborização, canteiros e pequenos jardins não podem ser classificados como áreas verdes, más sim, vistos como verde de acompanhamento viário, por não apresentar características dentro do contexto das áreas verdes, pertencendo nesse caso aos sistemas de espaços construídos ou espaços de integração urbana conforme citado anteriormente pelos autores.

Com intuito de solucionar o dilema entre os diferentes termos que buscam definir e categorizar esses locais Llardent (1982, p. 151), citado por Londe e Mendes (2014) expõe conceitos como: 
Sistemas de espaços livres: Conjunto de espaços urbanos ao ar livre destinados ao pedestre para o descanso, o passeio, a prática esportiva e, em geral, o recreio e entretenimento em sua hora de ócio. Espaço livre: Quaisquer das distintas áreas verdes que formam o sistema de espaços livres. Zonas verdes, espaços verdes, áreas verdes, equipamento verde: Qualquer espaço livre no qual predominam as áreas plantadas de vegetação, correspondendo, em geral, o que se conhece como parques, jardins ou praças (Llardent, 1982, p. 151, apud Londe e Mendes, 2014).

Se compararmos os conceitos expostos Llardent (1982) com os de Cavalheiro et al. (1999) veremos que a principal diferença é que um aborda a questão dos espaços construídos na cidade, tais como casas, indústrias e comércios, enquanto o outro divide o espaço livre em duas categorias que são os sistemas de espaços livres voltados para descanso e prática esportiva em geral, e, o espaço livre que engloba qualquer área verde.

Através das idéias expostas, levamos em consideração o conceito definido por Cavalheiro et al. (1999), estabelecendo que os espaços livres são ambientes não construídos e que a área verde é uma subcategoria de espaço livre tendo como componente primordial de sua estrutura a vegetação.

Conforme a Figura 2 é possível visualizar uma adaptação realizada a partir de Buccherri e Nucci (2006) com base nos conceitos e ideias de Cavalheiro et al. (1999) para classificação das praças como áreas verdes ou espaços livres dentro da cidade de Montes Claros.

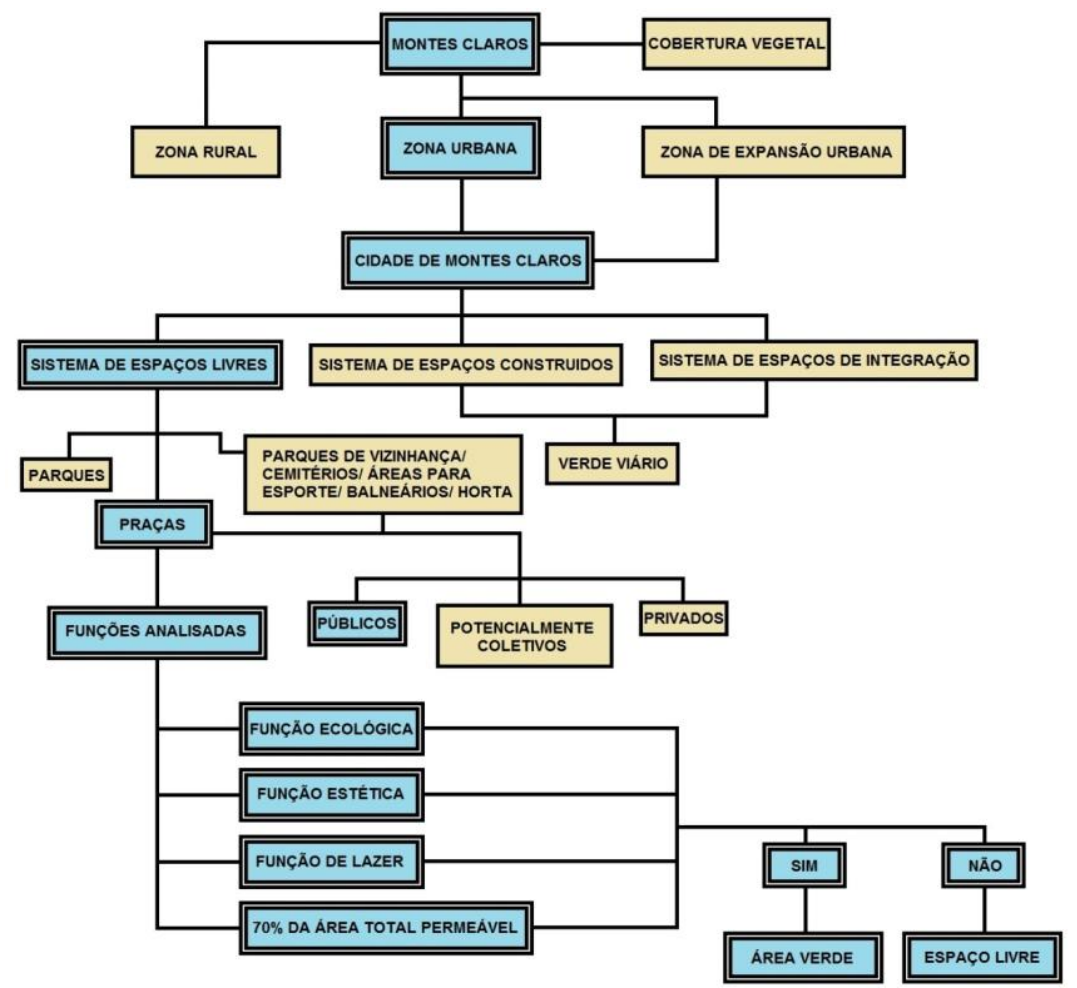

Figura 2. Organograma de Classificação de Verde Urbano Adaptado de Buccheri e Nucci (2006). Fonte: RODRIGUES, 2016. 
As praças dentro do perímetro urbano da cidade de Montes Claros se encontram distribuídas de forma heterogênea, grande parte delas concentradas na região central (Figura 3).

Viero e Filho (2009) conceituam as praças como espaços públicos dentro do perímetro urbano que não possuam edificação, propiciando assim um ambiente voltado para a convivência ou recreação em benefício da população. O precursor desse espaço dentro das cidades é conhecido como ágora advinda da Grécia que significa "lugar de reunião", sendo um local aberto onde às pessoas se reuniam para discussões e debates políticos (MACEDO e ROBBA, 2002).

Dentre os 135 loteamentos em que a cidade de Montes Claros é dividida, 52 loteamentos possuem praças dentro do seu perímetro e 83 não apresenta praças, estes loteamentos estão localizados em grande parte na borda da cidade e alguns próximos à área central. Muitos deles abrigam uma população de menor poder aquisitivo e apresentam uma estrutura limitada, pois, trata-se de locais que foram ocupados recentemente, em função disso ainda não possuem praças consolidadas.

Nem todas as praças que foram destacadas podem ser consideradas como áreas verdes, dentro da cidade foram localizadas 96 praças, todas foram analisadas conforme suas funções (Ecológica, Estética, Lazer e Área Permeável 70\%), nível de qualidade e posteriormente classificadas como espaço livre ou área verde. Dessas praças 81 foram classificadas como espaços livres, por apresentarem parte ou nenhuma das funções para ser designada como área verde e 16 delas foram consideradas como áreas verdes por apresentarem todas as funções.

Grande parte dessas áreas verdes encontra-se distribuídas de forma desigual dentro do perímetro da cidade, destacando que elas estão localizadas em loteamentos específicos, dessa forma, deixa de abranger e beneficiar grande parte da população. As áreas verdes mapeadas estão distribuídas especificamente nos loteamentos: Todos os Santos, Centro, Santa Rita, São João, Major Prates, Morada do Parque, Maria Cândida, Maracanã, Santos Reis, JK e Guarujá. 


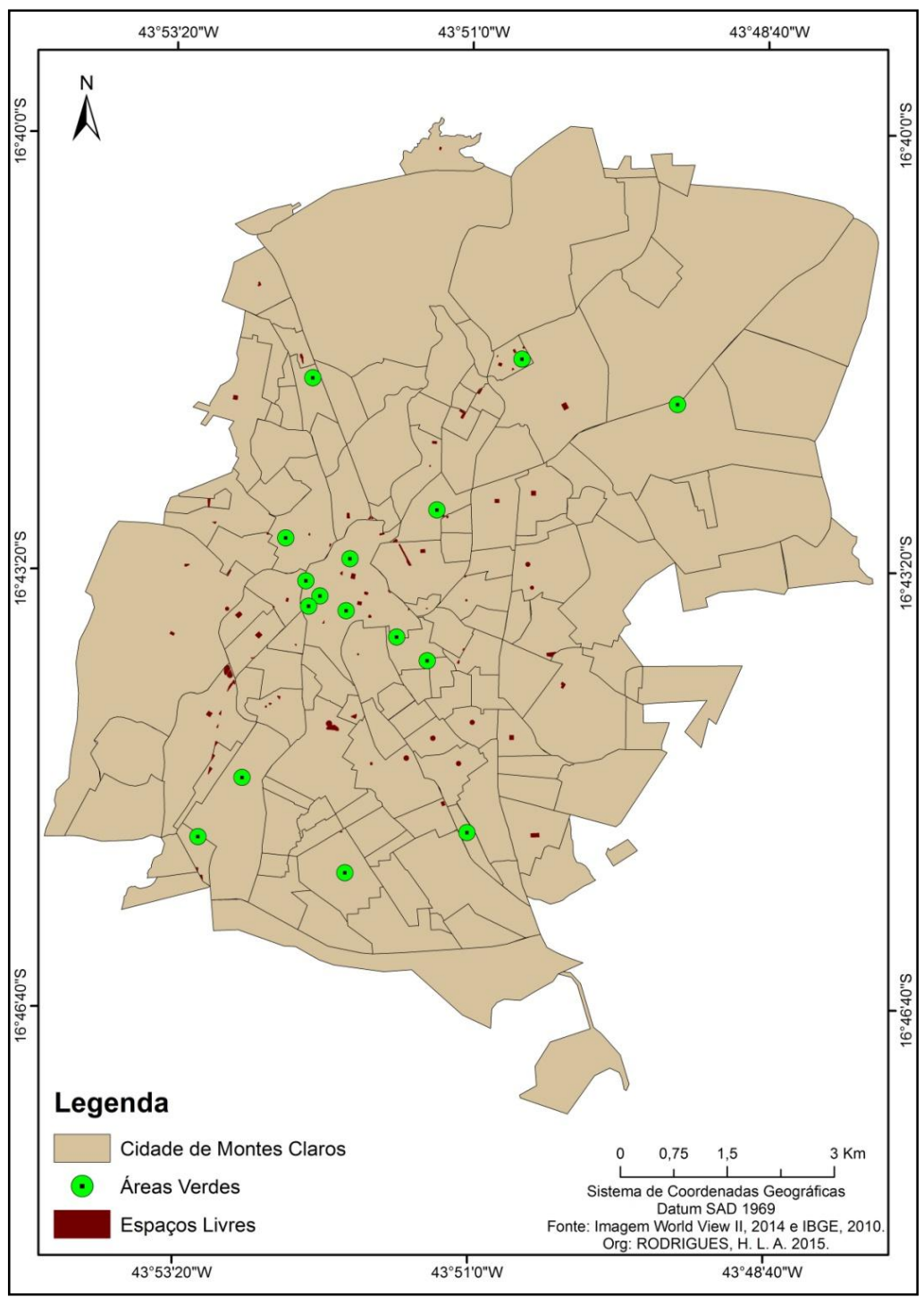

Figura 3. Localização e Classificação das Praças na Cidade de Montes Claros - MG. Fonte: IBGE, 2010 e Imagens World View-II, 2014.

As praças encontradas estão expostas (Tabela 1) conforme seus nomes, mas algumas não o possuem, sendo então identificadas através de um número $\mathrm{X}$, juntamente com o nome do loteamento onde se localiza, sendo que 55 nomes das praças foram obtidos a partir de placas de identificação fixadas no local e 41 não havia identificador no local.

As áreas ocupadas pelas praças variam muito, há aquelas que apresentam uma maior extensão como a Praça Flamarion Wanderley no loteamento São José (773,7 m2), Praça 02 no loteamento Guarujá (685,47 m2) dentre as maiores é a única que foi classificada como área verde, está localizada na entrada do aeroporto da cidade, a Praça Presidente Tancredo Neves no loteamento Canelas (657,75 
m2) ao lado da rodoviária, a Praça Itapetinga no loteamento São João (636,02 m2) e a Praça dos Jatobás localizada no loteamento Morada do Sol (643,79 m2).

Já outras, se mostram menores como a Praça 32 no loteamento Vila Regina (38,50 m2), a Praça 13 no loteamento JK (42,14 m2), e a Praça 30 no loteamento Jardim Santa Maria (63,12 m2). Dessas praças com menor área destacada nenhuma foi classificada como área verde devido às funções apresentadas por elas não atenderem aos requisitos expostos.

Dentre todas as praças, 31 delas possuíam qualidade ruim por apresentar somente uma ou nenhuma das quatro funções determinadas, 30 possuíam qualidade regular apresentando duas funções, 20 apresentaram qualidade boa por possuir três funções e somente 16 foram classificadas como área verde por apresentar as quatro funções.

Essas funções (Ecológica, Estética, Lazer e Área Permeável 70\%) apresentam uma distribuição diferenciada em cada praça, a função ecológica pode ser observada em 21 delas, a parte estética abrange 58 praças, áreas destinadas ao lazer englobam 71 praças e do total de praças mapeadas, somente 54 delas apresentaram área permeável de 70\%, assim, conforme os dados, nenhuma das funções abordadas competem a todas as praças.

\begin{tabular}{|c|c|c|c|c|}
\hline Nome & Área $\left(\mathrm{m}^{2}\right)$ & Funções & Classificação & Qualidade \\
\hline $\begin{array}{c}\text { Praça Dr. Carlos } \\
\text { Versiani }\end{array}$ & 271,75 & Estética, Lazer & Espaço Livre & Regular \\
\hline Praça Dr. João Alves & 193,32 & Lazer & Espaço Livre & Ruim \\
\hline Praça Pio XII & 155,31 & Lazer & Espaço Livre & Ruim \\
\hline Praça Coronel Ribeiro & 198,09 & $\begin{array}{c}\text { Ecológica, Estética, } \\
\text { Lazer, Área Permeável } \\
70 \%\end{array}$ & Área Verde & Muito Bom \\
\hline Praça Honorato Alves & 278,76 & $\begin{array}{c}\text { Ecológica, Estética, } \\
\text { Lazer, Área Permeável } \\
70 \%\end{array}$ & Área Verde & Muito Bom \\
\hline Praça Dr. Chaves & 304,14 & $\begin{array}{c}\text { Ecológica, Estética, } \\
\text { Lazer, Área Permeável } \\
70 \%\end{array}$ & Área Verde & Muito Bom \\
\hline Praça Itapetinga & 636,02 & $\begin{array}{c}\text { Ecológica, Estética, } \\
\text { Lazer, Área Permeável } \\
70 \%\end{array}$ & Área Verde & Muito Bom \\
\hline Praça João Catoni & 142,97 & Lazer, Área Permeável & Espaço Livre & Regular \\
\hline
\end{tabular}




\begin{tabular}{|c|c|c|c|c|}
\hline \multicolumn{5}{|c|}{$70 \%$} \\
\hline $\begin{array}{c}\text { Praça } 01 \text { (Todos os } \\
\text { Santos) }\end{array}$ & 380,34 & $\begin{array}{c}\text { Ecológica, Estética, } \\
\text { Lazer, Área Permeável } \\
70 \%\end{array}$ & Área Verde & Muito Bom \\
\hline $\begin{array}{c}\text { Praça Ubaldino de } \\
\text { Assis }\end{array}$ & 290,50 & $\begin{array}{c}\text { Ecológica, Estética, } \\
\text { Lazer }\end{array}$ & Espaço Livre & Bom \\
\hline $\begin{array}{c}\text { Praça Marcilio Jose } \\
\text { Barros Lins de } \\
\text { Albuquerque }\end{array}$ & 458,34 & Estética, Lazer & Espaço Livre & Regular \\
\hline Praça dos Jatobás & 643,79 & --- & Espaço Livre & Ruim \\
\hline $\begin{array}{c}\text { Praça Evangelina } \\
\text { Batista }\end{array}$ & 482,66 & $\begin{array}{c}\text { Ecológica, Estética, } \\
\text { Lazer, Área Permeável } \\
70 \%\end{array}$ & Área Verde & Muito Bom \\
\hline
\end{tabular}

Pcológica, Estética,

Praça Orpheu Froes $\quad 377,99$ Lazer, Área Permeável Área Verde Buito Bom

\begin{tabular}{|c|c|c|c|c|}
\hline \multicolumn{5}{|c|}{$70 \%$} \\
\hline Praça Igor Xavier & 139,79 & Estética, Lazer & Espaço Livre & Regular \\
\hline $\begin{array}{c}\text { Praça João Batista de } \\
\text { Moura }\end{array}$ & 293,52 & Lazer & Espaço Livre & Ruim \\
\hline $\begin{array}{c}\text { Praça Beato Francisco } \\
\text { Coll }\end{array}$ & 520,23 & $\begin{array}{c}\text { Ecológica, Estética, } \\
\text { Lazer, Área Permeável } \\
70 \%\end{array}$ & Área Verde & Muito Bom \\
\hline Praça Padre Dudu & 149,26 & --- & Espaço Livre & Ruim \\
\hline Praça Joel Cardoso & 277,55 & Estética, Lazer & Espaço Livre & Regular \\
\hline $\begin{array}{c}\text { Praça Madri Olmira } \\
\text { Lacerda Franca }\end{array}$ & 262,52 & $\begin{array}{c}\text { Estética, Lazer, Área } \\
\text { Permeável 70\% }\end{array}$ & Espaço Livre & Bom \\
\hline Praça Rotery & 270,36 & $\begin{array}{c}\text { Ecológica, Estética, } \\
\text { Lazer }\end{array}$ & Espaço Livre & Bom \\
\hline Praça Raul Soares & 132,10 & $\begin{array}{c}\text { Estética, Lazer, Área } \\
\text { Permeável 70\% }\end{array}$ & Espaço Livre & Bom \\
\hline Praça Elis Regina & 187,63 & $\begin{array}{l}\text { Estética, Lazer, Área } \\
\text { Permeável 70\% }\end{array}$ & Espaço Livre & Bom \\
\hline Praça João Soares & 210,78 & Lazer & Espaço Livre & Ruim \\
\hline Praça 02 (Guarujá) & 685,47 & $\begin{array}{c}\text { Ecológica, Estética, } \\
\text { Lazer, Área Permeável } \\
70 \%\end{array}$ & Área Verde & Muito Bom \\
\hline Praça Geraldo Prates & 195,23 & Estética, Lazer & Espaço Livre & Regular \\
\hline $\begin{array}{c}\text { Praça Nossa Senhora } \\
\text { Aparecida }\end{array}$ & 205,53 & Área Permeável 70\% & Espaço Livre & Ruim \\
\hline Praça São Sebastião & 208,79 & Lazer & Espaço Livre & Ruim \\
\hline Praça Nosso Lar & 214,20 & Lazer & Espaço Livre & Ruim \\
\hline $\begin{array}{c}\text { Praça Nossa Senhora } \\
\text { de Lourdes }\end{array}$ & 77,57 & --- & Espaço Livre & Ruim \\
\hline $\begin{array}{c}\text { Praça Geraldo } \\
\text { Magalhães Gomes }\end{array}$ & 77,49 & $\begin{array}{c}\text { Estética, Lazer, Área } \\
\text { Permeável 70\% }\end{array}$ & Espaço Livre & Bom \\
\hline $\begin{array}{c}\text { Praça José Fernandes } \\
\text { Araújo }\end{array}$ & 70,23 & Lazer & Espaço Livre & Ruim \\
\hline Praça Rita Fernandes & 65,14 & Área Permeável 70\% & Espaço Livre & Ruim \\
\hline $\begin{array}{c}\text { Praça Altino Pereira } \\
\text { de Melo }\end{array}$ & 82,55 & $\begin{array}{l}\text { Ecológica, Estética, } \\
\text { Área Permeável 70\% }\end{array}$ & Espaço Livre & Bom \\
\hline Praça Capitão Enéas & 111,04 & $\begin{array}{c}\text { Estética, Lazer, Área } \\
\text { Permeável 70\% }\end{array}$ & Espaço Livre & Bom \\
\hline
\end{tabular}




\begin{tabular}{|c|c|c|c|c|}
\hline Praça Robson Costa & 154,79 & $\begin{array}{c}\text { Ecológica, Estética, } \\
\text { Lazer, Área Permeável } \\
70 \%\end{array}$ & Área Verde & Muito Bom \\
\hline $\begin{array}{l}\text { Praça Engenheiro } \\
\text { Joaquim Costa }\end{array}$ & 185,35 & $\begin{array}{c}\text { Estética, Área } \\
\text { Permeável 70\% }\end{array}$ & Espaço Livre & Regular \\
\hline Praça Bom Jesus & 145,47 & Estética, Lazer & Espaço Livre & Regular \\
\hline $\begin{array}{c}\text { Praça Marcelino } \\
\text { Champagnat }\end{array}$ & 134,7 & $\begin{array}{c}\text { Estética, Lazer, Área } \\
\text { Permeável 70\% }\end{array}$ & Espaço Livre & Bom \\
\hline $\begin{array}{c}\text { Praça Ezequiel } \\
\text { Rodrigues Monção }\end{array}$ & 82,58 & Estética, Lazer & Espaço Livre & Regular \\
\hline Praça 03 (Cintra) & 96,96 & Lazer & Espaço Livre & Ruim \\
\hline Praça 04 (Cintra) & 129,66 & $\begin{array}{c}\text { Lazer, Área Permeável } \\
70 \%\end{array}$ & Espaço Livre & Regular \\
\hline $\begin{array}{c}\text { Praça Professora } \\
\text { Luciola Dias Moreira }\end{array}$ & 231,85 & Área Permeável 70\% & Espaço Livre & Ruim \\
\hline Praça Adail Sarmento & 152,09 & $\begin{array}{c}\text { Estética, Área } \\
\text { Permeável 70\% }\end{array}$ & Espaço Livre & Regular \\
\hline Praça Marta Pimenta & 118,19 & Área Permeável 70\% & Espaço Livre & Ruim \\
\hline $\begin{array}{c}\text { Praça Coronel Carlos } \\
\text { Leite }\end{array}$ & 233,84 & Estética, Lazer & Espaço Livre & Regular \\
\hline $\begin{array}{c}\text { Praça Presidente } \\
\text { Tancredo Neves }\end{array}$ & 657,75 & $\begin{array}{c}\text { Estética, Área } \\
\text { Permeável 70\% }\end{array}$ & Espaço Livre & Regular \\
\hline Praça Manoel José & 220,77 & $\begin{array}{c}\text { Lazer, Área Permeável } \\
70 \%\end{array}$ & Espaço Livre & Regular \\
\hline $\begin{array}{c}\text { Praça Flamarion } \\
\text { Wanderley }\end{array}$ & 773,7 & Estética, Lazer & Espaço Livre & Regular \\
\hline $\begin{array}{c}\text { Praça } 05 \text { (Todos os } \\
\text { Santos) }\end{array}$ & 87,69 & Estética, Lazer & Espaço Livre & Regular \\
\hline $\begin{array}{c}\text { Praça } 06 \text { (Vila } \\
\text { Atlântida) }\end{array}$ & 242,78 & $\begin{array}{c}\text { Estética, Lazer, Área } \\
\text { Permeável 70\% }\end{array}$ & Espaço Livre & Bom \\
\hline Praça Duque de Caxias & 239,40 & $\begin{array}{c}\text { Ecológica, Estética, } \\
\text { Lazer, Área Permeável } \\
70 \%\end{array}$ & Área Verde & Muito Bom \\
\hline Praça Idalina Lopes & 301,42 & $\begin{array}{c}\text { Ecológica, Estética, } \\
\text { Lazer, Área Permeável } \\
70 \%\end{array}$ & Área Verde & Muito Bom \\
\hline $\begin{array}{c}\text { Praça Rhandal Juliano } \\
\text { Maia Almeida }\end{array}$ & 71,69 & Lazer & Espaço Livre & Ruim \\
\hline Praça 07 (Melo) & 168,32 & $\begin{array}{c}\text { Lazer, Área Permeável } \\
70 \%\end{array}$ & Espaço Livre & Regular \\
\hline Praça Elvira Aguiar & 257,48 & Estética, Lazer & Espaço Livre & Regular \\
\hline Praça 08 (JK) & 151,97 & $\begin{array}{c}\text { Estética, Lazer, Área } \\
\text { Permeável 70\% }\end{array}$ & Espaço Livre & Bom \\
\hline Praça 09 (JK) & 275,85 & $\begin{array}{c}\text { Ecológica, Estética, } \\
\text { Lazer, Área Permeável } \\
70 \%\end{array}$ & Área Verde & Muito Bom \\
\hline $\begin{array}{c}\text { Praça Antônio Jorge } \\
\text { da Silva }\end{array}$ & 85,81 & --- & Espaço Livre & Ruim \\
\hline Praça 10 (JK) & 157,68 & $\begin{array}{c}\text { Lazer, Área Permeável } \\
70 \%\end{array}$ & Espaço Livre & Regular \\
\hline Praça Girrasol & 198,50 & Área Permeável 70\% & Espaço Livre & Ruim \\
\hline Praça 11 (JK) & 87,77 & Lazer & Espaço Livre & Ruim \\
\hline Praça 12 (JK) & 83,15 & Lazer & Espaço Livre & Ruim \\
\hline
\end{tabular}




\begin{tabular}{|c|c|c|c|c|}
\hline Praça 13 (JK) & 42,14 & --- & Espaço Livre & Ruim \\
\hline $\begin{array}{c}\text { Praça Godofredo } \\
\text { Guedes }\end{array}$ & 108,81 & $\begin{array}{c}\text { Ecológica, Estética, } \\
\text { Lazer, Área Permeável } \\
70 \%\end{array}$ & Área Verde & Bom \\
\hline $\begin{array}{c}\text { Praça } 14 \text { (Santo } \\
\text { Antonio) }\end{array}$ & 245,19 & Estética, Lazer & Espaço Livre & Regular \\
\hline Praça Reginauro Silva & 160,30 & Estética & Espaço Livre & Ruim \\
\hline $\begin{array}{c}\text { Praça } 15 \text { (Morada do } \\
\text { Sol) }\end{array}$ & 316,85 & Estética & Espaço Livre & Ruim \\
\hline $\begin{array}{c}\text { Praça } 16 \text { (Augusta } \\
\text { Mota) }\end{array}$ & 231,41 & $\begin{array}{c}\text { Estética, Área } \\
\text { Permeável 70\% }\end{array}$ & Espaço Livre & Regular \\
\hline Praça 17 (Santa Lucia) & 322,83 & $\begin{array}{c}\text { Lazer, Área Permeável } \\
70 \%\end{array}$ & Espaço Livre & Regular \\
\hline $\begin{array}{c}\text { Praça } 18 \text { (Monte } \\
\text { Carmelo) }\end{array}$ & 156,21 & Estética & Espaço Livre & Ruim \\
\hline $\begin{array}{c}\text { Praça } 19 \text { (São Judas } \\
\text { Tadeu) }\end{array}$ & 114,69 & Lazer & Espaço Livre & Ruim \\
\hline Praça 20 (Ibituruna) & 170,06 & $\begin{array}{c}\text { Estética, Lazer, Área } \\
\text { Permeável 70\% }\end{array}$ & Espaço Livre & Bom \\
\hline Praça 21 (Ibituruna) & 160,10 & $\begin{array}{c}\text { Estética, Área } \\
\text { Permeável 70\% }\end{array}$ & Espaço Livre & Regular \\
\hline Praça 22 (Ibituruna) & 237,29 & $\begin{array}{l}\text { Estética, Lazer, Área } \\
\text { Permeável 70\% }\end{array}$ & Espaço Livre & Bom \\
\hline Praça 23 (Santos Reis) & 193,84 & $\begin{array}{c}\text { Ecológica, Estética, } \\
\text { Lazer, Área Permeável } \\
70 \%\end{array}$ & Área Verde & Muito Bom \\
\hline Praça 24 (Vila Áurea) & 339,47 & Lazer & Espaço Livre & Ruim \\
\hline $\begin{array}{c}\text { Praça } 25 \text { (Jardim } \\
\text { Eldorado) }\end{array}$ & 167,97 & $\begin{array}{c}\text { Estética, Lazer, Área } \\
\text { Permeável 70\% }\end{array}$ & Espaço Livre & Bom \\
\hline $\begin{array}{c}\text { Praça } 26 \text { (Cidade } \\
\text { Industrial) }\end{array}$ & 129,81 & Área Permeável 70\% & Espaço Livre & Ruim \\
\hline $\begin{array}{c}\text { Praça } 27 \text { (Morada do } \\
\text { Parque) }\end{array}$ & 129,62 & Estética, Lazer & Espaço Livre & Regular \\
\hline $\begin{array}{c}\text { Praça } 28 \text { (Sagrada } \\
\text { Família) }\end{array}$ & 158,08 & Estética, Lazer & Espaço Livre & Regular \\
\hline $\begin{array}{c}\text { Praça } 29 \text { (Sagrada } \\
\text { Família) }\end{array}$ & 118,41 & $\begin{array}{c}\text { Ecológica, Lazer, Área } \\
\text { Permeável 70\% }\end{array}$ & Espaço Livre & Bom \\
\hline $\begin{array}{l}\text { Praça } 30 \text { (Jardim } \\
\text { Santa Maria) }\end{array}$ & 63,12 & --- & Espaço Livre & Ruim \\
\hline $\begin{array}{c}\text { Praça } 31 \text { (Vila } \\
\text { Brasília) }\end{array}$ & 247,7 & $\begin{array}{c}\text { Estética, Área } \\
\text { Permeável 70\% }\end{array}$ & Espaço Livre & Regular \\
\hline Praça 32 (Vila Regina) & 38,50 & --- & Espaço Livre & Ruim \\
\hline $\begin{array}{c}\text { Praça } 33 \text { (Todos os } \\
\text { Santos) }\end{array}$ & 107,92 & $\begin{array}{l}\text { Estética, Lazer, Área } \\
\text { Permeável 70\% }\end{array}$ & Espaço Livre & Bom \\
\hline Praça Portugal & 129,37 & Lazer & Espaço Livre & Ruim \\
\hline $\begin{array}{c}\text { Praça } 34 \text { (Maria } \\
\text { Cândida) }\end{array}$ & 150,79 & $\begin{array}{c}\text { Ecológica, Estética, } \\
\text { Lazer, Área Permeável } \\
70 \%\end{array}$ & Área Verde & Muito Bom \\
\hline $\begin{array}{c}\text { Praça } 35 \text { (Antônio } \\
\text { Pimenta) }\end{array}$ & 216,58 & $\begin{array}{c}\text { Lazer, Área Permeável } \\
70 \%\end{array}$ & Espaço Livre & Regular \\
\hline $\begin{array}{c}\text { Praça } 36 \text { (Cidade } \\
\text { Cristo Rei) }\end{array}$ & 99,08 & Ecológica, Lazer & Espaço Livre & Regular \\
\hline Praça 37 (Vera Cruz) & 225,84 & Estética, Lazer, Área & Espaça Livre & Bom \\
\hline
\end{tabular}




\begin{tabular}{|c|c|c|c|c|}
\hline \multicolumn{5}{|c|}{ Permeável 70\% } \\
\hline Praça 38 (Planalto) & 315,09 & $\begin{array}{c}\text { Lazer, Área Permeável } \\
70 \%\end{array}$ & Espaço Livre & Regular \\
\hline $\begin{array}{c}\text { Praça } 39 \text { (Vila } \\
\text { Tiradentes) }\end{array}$ & 204,66 & $\begin{array}{c}\text { Estética, Lazer, Área } \\
\text { Permeável 70\% }\end{array}$ & Espaço Livre & Bom \\
\hline Praça 40 (Renascença) & 367,80 & $\begin{array}{c}\text { Estética, Lazer, Área } \\
\text { Permeável 70\% }\end{array}$ & Espaço Livre & Bom \\
\hline Praça 41 (Cristo Rei) & 188,83 & Lazer & Espaço Livre & Ruim \\
\hline $\begin{array}{c}\text { Praça Doutor Oscar } \\
\text { Romero }\end{array}$ & 151,98 & $\begin{array}{c}\text { Estética, Área } \\
\text { Permeável 70\% }\end{array}$ & Espaço Livre & Regular \\
\hline
\end{tabular}

Figura 3. Caracterização e classificação das praças na cidade de Montes Claros (MG). Org: RODRIGUES, H. L. A. 2016.

As áreas verdes identificadas compreendem diversas localidades da cidade de Montes Claros, desde loteamentos com menor ao maior poder aquisitivo. No Centro localizam-se as praças Coronel Ribeiro (A), Honorato Alves (B), Dr. Chaves (C), Robson Costa (D) (Figura 4) e Godofredo Guedes, abrangem uma área que possui uma grande concentração de pontos comerciais e menor de moradores residenciais, são parcialmente pavimentadas, apresenta áreas permeáveis e possuem vegetação de grande, médio e pequeno porte, plantas de ornamentação e gramíneas.

O fluxo de pessoas é intenso, e no seu entorno observamos pontos comerciais diversificados, farmácias, escolas, hospitais e lojas de objetos afins. Grande parte das pessoas que frequentam diariamente permanece por um curto período de tempo, mas, alguns como estudantes, idosos, mototaxistas, trabalhadores dos comércios locais ou até mesmo pessoas de outros locais da cidade, vão ao centro para fazer o uso de algum tipo de serviço e ficam no local para aproveitar um momento de lazer, descansando após o almoço, conversando ou dormindo por um breve momento. 


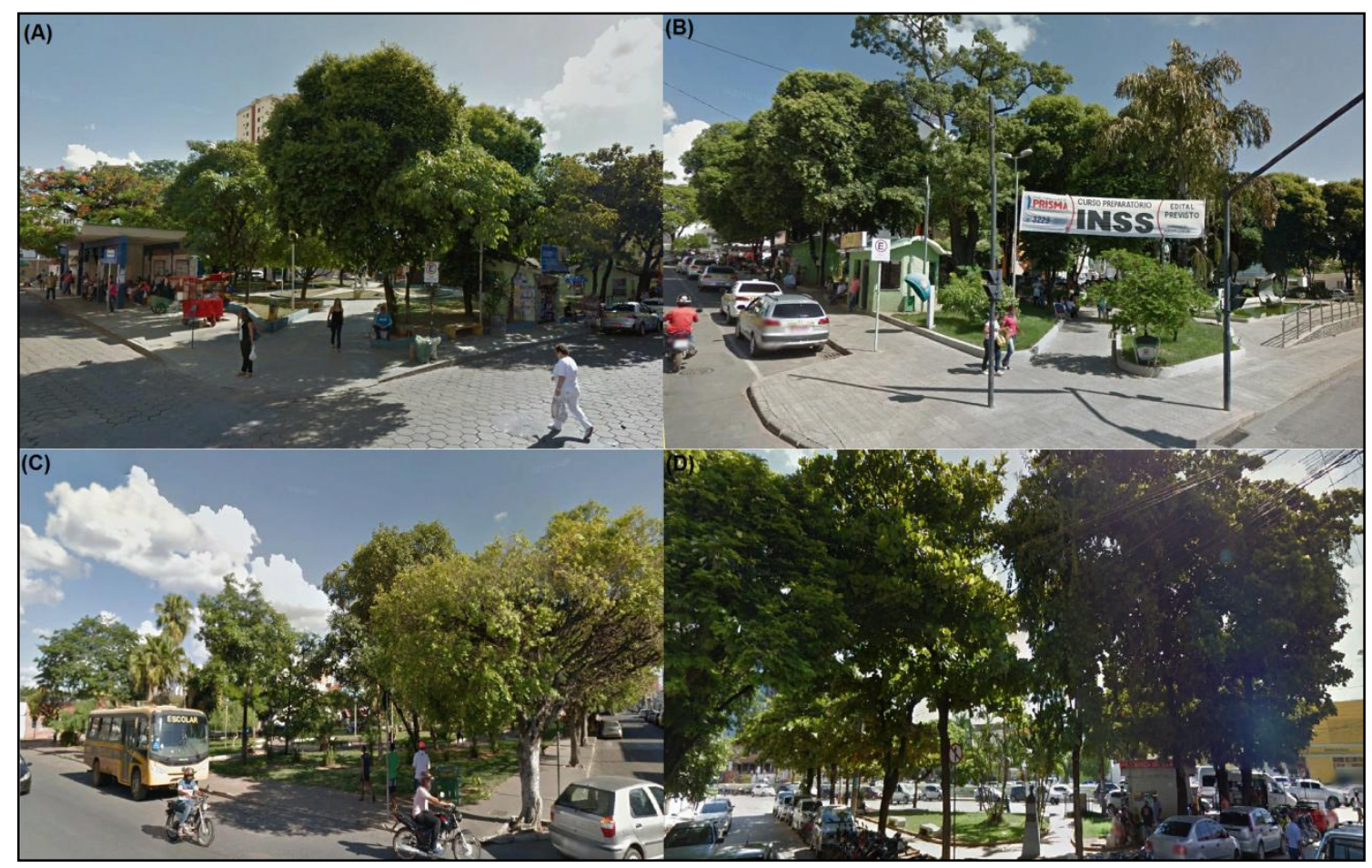

Figura 4. Áreas Verdes no loteamento Centro na Cidade de Montes Claros. Fonte: GOOGLE EARTH, 2016.

Os loteamentos Santa Rita, São João e Todos os Santos fazem limite com o Centro e também possuem praças classificadas como áreas verdes, tais como a Duque de Caxias (A), Idalina Lopes (B), Itapetinga (C) e a praça 01 (D) (Figura 5) localizada nas proximidades da Universidade Estadual de Montes Claros (Unimontes). No entorno a maior parte das edificações encontradas são de uso residencial, mas, também se encontra alguns comércios nas proximidades como restaurantes, bares, lanchonetes e pequenos supermercados.

Sua estrutura é bem diversificada apresentando áreas pavimentadas e permeáveis com concentração de fauna e flora em diversas escalas desde pequenas plantas e grandes árvores a pássaros e insetos. A circulação de pessoas é reduzida quando comparada às praças encontradas na região central da cidade, pois a grande maioria dos seus frequentadores pertencem ao loteamento, com exceção da praça 01 no loteamento Todos os Santos que é bastante frequentada pelos universitários da Unimontes e por possuir uma pista de Skate, que atrai praticantes do esporte de diversos locais da cidade principalmente no período noturno sendo o horário de maior movimento. 


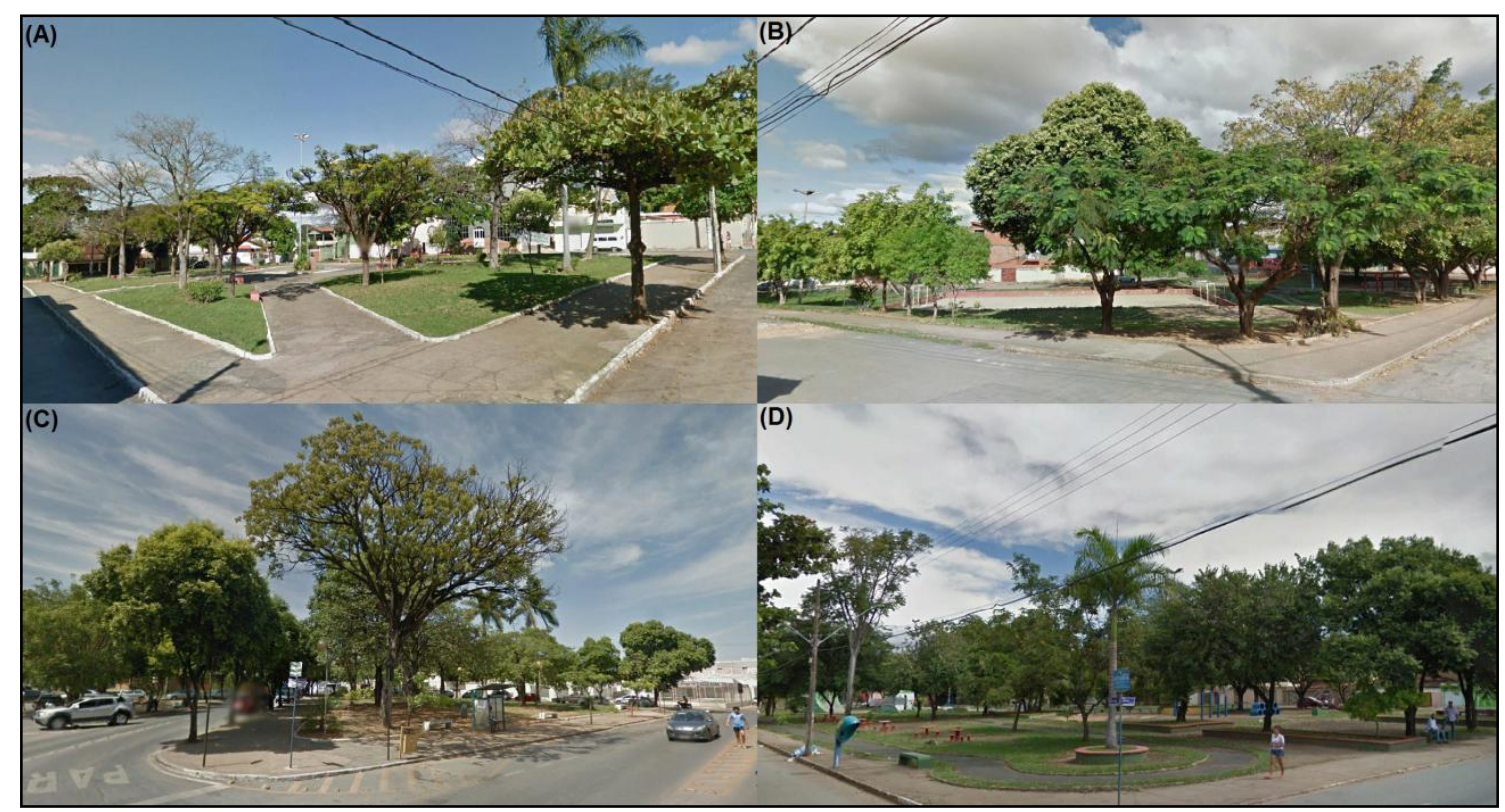

Figura 5. Áreas Verdes nos Loteamentos Santa Rita, São João e Todos os Santos na cidade de Montes Claros. Fonte: GOOGLE EARTH, 2016.

No norte da cidade, encontramos mais três áreas verdes localizadas nos loteamentos Santos Reis, JK e Guarujá sendo a Praça 23 (A), a Praça 09 (B) e a Praça 02 (C) - (Figura 6), que se encontra na entrada do Aeroporto da cidade. Estas praças estão à uma distância significativa da área central, onde a população predominante possui um menor poder aquisitivo e a concentração de pontos comerciais e locais para lazer é mínima.

Possuem uma estrutura não muito diferenciada das demais com bancos, vegetação diversificada, presença de pequenos animais, locais para prática de exercícios, áreas permeáveis e pavimentadas. São lugares esteticamente agradáveis que são utilizados para descanso e lazer da população local, a praça 02 no loteamento Guarujá por exemplo é bastante usada para prática de caminhadas.

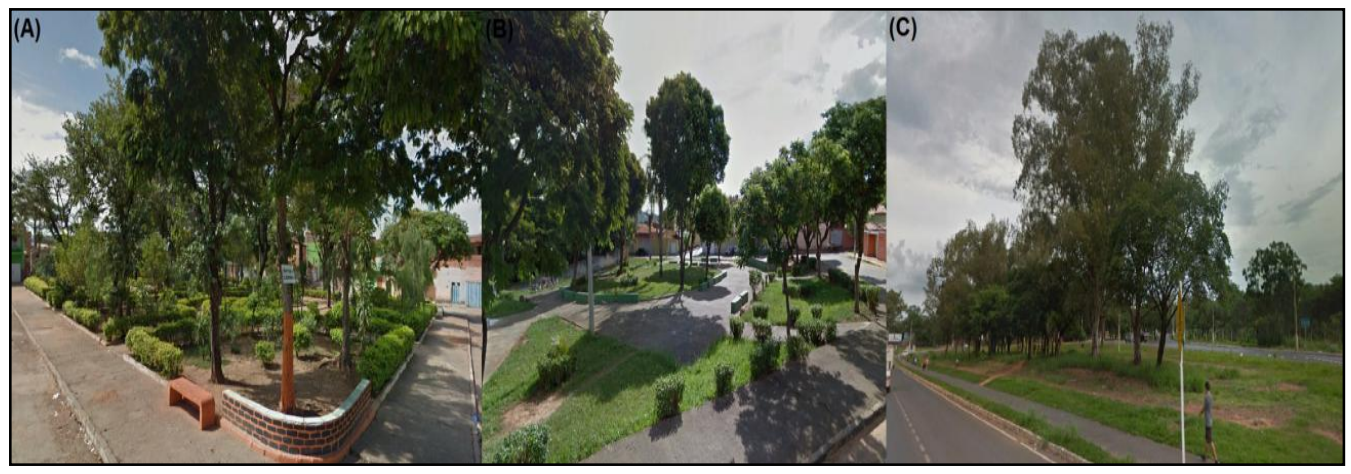

Figura 6. Áreas Verdes nos Loteamentos Santos Reis, JK e Guarujá na Cidade de Montes Claros. Fonte: GOOGLE EARTH, 2016. 
Ao sul estão outras quatro praças classificadas como áreas verdes dentro do perímetro urbano, sendo elas: Praça Evangelina Batista (A), Praça Orpheu Froés (B), Praça Beato Francisco Coll (C) e Praça 34 (D) - (Figura 7), posicionadas nos loteamentos Major Prates, Morada do Parque, Maracanã e Maria Cândida. Essas quatro áreas verdes destacadas estão a uma distância considerável tanto entre elas quanto da região central, diversificando dessa maneira a estrutura e forma dos locais onde são encontradas.

As praças Evangelina Batista e Beato Francisco Coll, estão localizadas nos loteamentos Major Prates e Maracanã. Estes por sua vez, são considerados subcentros devido apresentar prestações de serviços diversificados e dinâmicas semelhantes ao centro.

O Morada do Parque onde localiza-se a Praça Orpheu Froés é um loteamento voltado para a ocupação residencial onde há a concentração de pessoas com maior poder aquisitivo, e a Praça 34 fixada no loteamento Maria Cândida possui uma população residencial com menor poder aquisitivo.

Quanto à estrutura das áreas verdes já ressaltadas, com relação à parte ecológica apresenta uma vegetação bem distribuída e concentração de pequenos animais. São áreas conservadas e chamativas, e em relação ao lazer, apresenta diversas opções como locais para repouso, quadra de futsal, pista de skate, parquinho para crianças e academia ao ar livre.

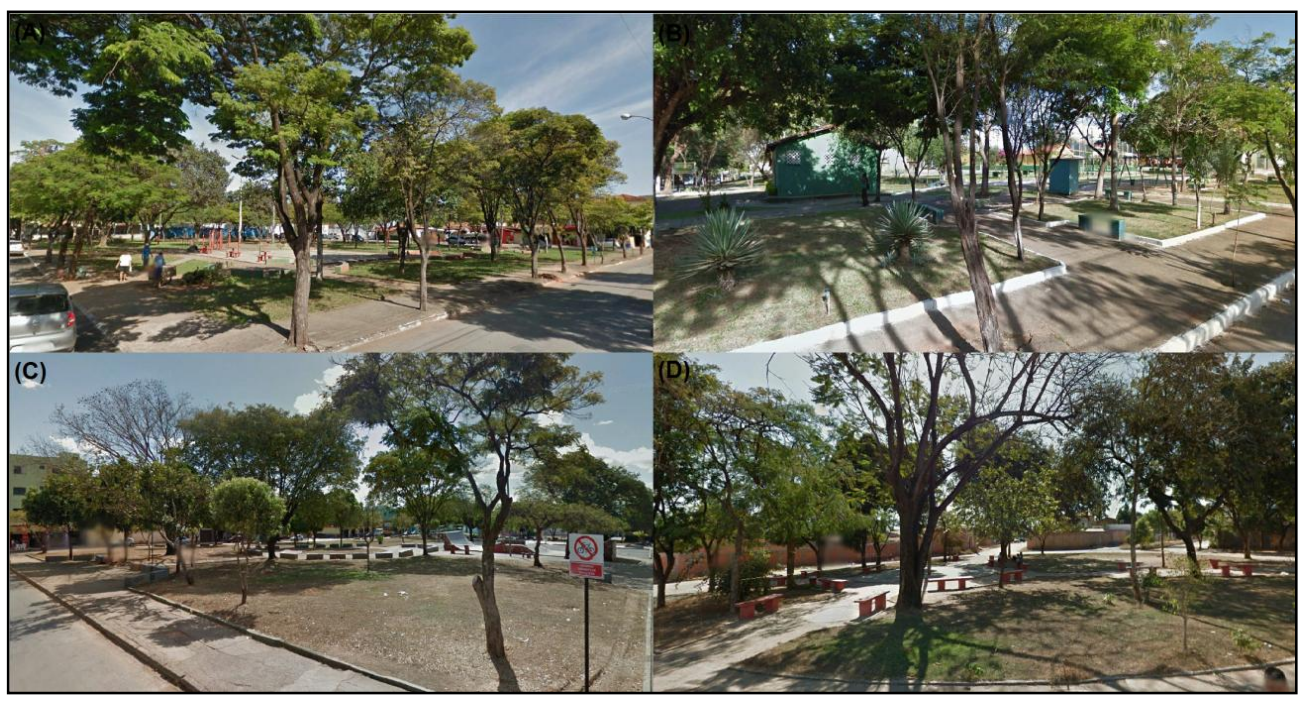

Figura 7. Áreas Verdes nos Loteamentos Santos Reis, JK e Guarujá na Cidade de Montes Claros. Fonte: GOOGLE EARTH, 2016. 
Conforme a análise feita e de acordo com os dados apresentados, a cidade de Montes Claros mostra uma quantia pequena de praças que podem ser consideradas como áreas verdes. Este fato ocorre, pois, muitos dos locais analisados não apresentaram as funções pertinentes conforme as idéias de Cavalheiro et al. (1999).

Muitos desses locais não têm uma boa estrutura, possuem uma quantidade mínima de solo permeável, pouca vegetação, poucas opções para lazer e não são esteticamente chamativos a população.

\section{CONSIDERAÇÕES FINAIS}

De modo geral, a metodologia aplicada no trabalho para análise e mapeamento das áreas verdes na cidade de Montes Claros, se mostrou bastante eficaz. Com base nos conceitos de Cavalheiro et al. (1999) que considera aspectos ecológicos, estéticos, de lazer e permeabilidade do local, as praças puderam ser classificadas e subdividas em espaço livre e área verde de acordo com as funções apresentadas por cada uma.

Com base nos produtos obtidos a partir das imagens de satélite de alta resolução espacial e do Sistema de Informação Geográfica (SIG) proporcionou a identificação, localização e mapeamento das praças na cidade de Montes Claros.

A partir do mapeamento das praças em Montes Claros, verificou-se a disposição heterogênea das áreas verdes na cidade, ocupando desde loteamentos com condições mais precárias até locais mais dinâmicos e estruturados, observando que ainda existem alguns locais que não dispõe dessas áreas.

Portanto, conclui-se que é necessário por parte da prefeitura, além do planejamento de novas áreas voltadas para o lazer e qualidade ambiental urbana, devem certificar a melhora na estrutura desses locais, tornando-os mais atrativos e consequentemente haverá um melhoramento da qualidade de vida da população. 


\section{REFERÊNCIAS}

BARGOS, D. C.; MATIAS, L. F. Áreas verdes urbanas: um estudo de revisão e proposta conceitual. Revista da Sociedade Brasileira de Arborização Urbana. Piracicaba, 2011. v. 6, p. 172-188. Disponível em:

<http://www.revsbau.esalq.usp.br/artigos_cientificos/artigo169-publicacao.pdf>. Acesso em: Novembro de 2016.

BUCCHERI FILHO, A. T.; NUCCI, J. C. Espaços livres, áreas verdes e cobertura vegetal no bairro Alto da XV, Curitiba Paraná. Revista do Departamento de Geografia (USP). São Paulo, 2006. v. 18, p. 48-59. Disponível em:

<http://www.geografia.fflch.usp.br/publicacoes/RDG/RDG_18/RDG18_048_\%20059.pdf>. Acesso em: Outubro de 2016.

CAVAlHeIRO, F.; GUZZO, P.; ROCHA, Y. T.; NUCCI, J. C. Proposição de terminologia para o verde urbano. Boletim Informativo da Sociedade Brasileira de Arborização Urbana. Rio de Janeiro, 1999. v. 7, n.3, p. 7-7. Disponível em: <http://www.labs.ufpr.br/site/wp-content/uploads/2014/09/cavalheiroetal_artigoscompletos_sbau_1999.pdf>.Acesso em: Outubro de 2016.

CAVAlHEIRO, F.; DEL PICCHIA, P. C. D. Áreas Verdes: conceitos, objetivos e diretrizes para o planejamento. In: Anais do $1^{\circ}$ Congresso Brasileiro Sobre Arborização Urbana e $4^{\circ}$ Encontro Nacional Sobre Arborização Urbana. Anais... Vitória, 1992. p. 29-38. Disponível em: <http://www.labs.ufpr.br/site/wpcontent/uploads/2014/07/cavalheiro_anaisdecongressos_cbau_1992.pdf >. Acesso em: Novembro de 2016.

IBGE , INSTITUTO BRASILEIRO DE GEOGRAFIA E ESTATÍSTICA. Histórico da cidade de Montes Claros em Minas Gerais. 2010. Disponível em:

$<$ http://www.cidades.ibge.gov.br/painel/historico.php?lang=\&codmun=314330\&search=minas-gerais $\mid$ montesclaros|infograficos:-historico $>$. Acesso em: Outubro de 2016.

LimA, A. M. L. P.; CAVAlheirO, F.; NUSSI, J. C.; SOUSA, M. A. L. B.; FIALHO, N.; PICCHIA, P. C. D. Problemas de utilização na conceituação de termos como espaços livres, áreas verdes e correlatos. In: Encontro Nacional sobre Arborização Urbana. Anais... São Luis. 1995. p. 539-553. Disponível em: <http://www.labs.ufpr.br/site/wpcontent/uploads/2014/07/lima_anaisdecongressos_cbau_1994.pdf $>$. Acesso em: Outubro de 2016.

LIMA, V.; AMORIM, M. C. C. T. A importância das áreas verdes para a qualidade ambiental das cidades. Revista Formação. Presidente Prudente, 2006. v. 13, p. 139-165. Disponível em:

$<$ http://revista.fct.unesp.br/index.php/formacao/article/viewFile/835/849>. Acesso em: Outubro de 2016.

LONDE, P. R.; MENDES, P. C. A Influencia das áreas verdes na qualidade de vida urbana. Revista Brasileira de Geografia Médica e da Saúde. Uberlândia, 2014. v. 10, p. 264-272. Disponível em:

<http://www.seer.ufu.br/index.php/hygeia/article/viewFile/26487/14869>. Acesso em: Novembro de 2016. MACEDO, S. S.; ROBBA, F. Praças brasileiras. São Paulo: Edusp, 2002.

MONTES CLAROS. Lei № 3.720, de 09 de Maio de 2007. Dispõe Sobre o Parcelamento do Solo Urbano e Loteamentos Fechados no Município de Montes Claros. Procuradoria Jurídica, Montes Claros - MG, 2007. Disponível em: <http://www.montesclaros.mg.gov.br/planodiretor/LEIS/lei-3720-07-parcelamento-do-solo-urbano.pdf>. Acesso em: Novembro de 2016.

NUCCI, J. C. Qualidade Ambiental e Adensamento Urbano: Um Estudo de Ecologia e Planejamento da Paisagem Aplicado ao Distrito de Santa Cecília (MSP). Humanistas/FFLCH-USP. Curitiba, 2008. v. 1, $2^{\text {a }}$ edição. Disponível em: $<$ http://www.labs.ufpr.br/site/arquivos/qldade_amb_aden_urbano.pdf >. Acesso em: Novembro de 2016. 